\title{
MEDUSA Y EL ESPEJO CÓNCAVO: LA RAIGAMBRE NORMATIVA DE LA VIOLENCIA SOBRE EL CUERPO
}

\author{
Ariel Martínez \\ doi: 10.11144/Javeriana.uph35-71.mecv
}

\section{RESUMEN}

A partir de las consideraciones de Adriana Cavarero sobre el lugar del cuerpo en las modalidades que adquiere la violencia contemporánea, se plantea un recorrido conceptual por ideas de Jacques Lacan, Judith Butler y Kaja Silverman para sostener, por un lado, un giro onto-epistemológico que entiende al cuerpo como efecto de normas sociales y, por otro lado, una reflexión ético-política respecto a los niveles de exposición violenta a los que son sometidos aquellos cuerpos excluidos de los marcos de inteligibilidad que tornan una vida vivible. Finalmente, como alternativa a los modos hegemónicos en que la representación opera en la configuración del cuerpo como totalidad y unicidad -que la teoría lacaniana vincula con el espejo plano- se postula el espejo cóncavo como posibilidad de otros modos, alternativos, de representación del cuerpo.

Palabras clave: cuerpo; violencia; representación; precaridad;

vulnerabilidad

Universidad Nacional de La Plata-CONICET, Buenos Aires, Argentina.

Correo electrónico: amartinez@psico.unlp.edu.ar

Para citar este artículo: Martínez, A. (2018). Medusa y el espejo cóncavo. La raigambre normativa de la violencia sobre el cuerpo. Universitas Philosophica, 35(71), pp. 21-52. ISSN 0120-5323, ISSN en línea 2346-2426. doi: 10.11144/Javeriana.uph35-71.mecv 


\title{
MEDUSA AND THE CONCAVE MIRROR: THE NORMATIVE ROOTS OF VIOLENCE ON THE BODY
}

\begin{abstract}
This article draws from Adriana Cavarero's considerations on the role of the body in diverse contemporary modalities of violence. We propose a conceptual path along some ideas from Jacques Lacan, Judith Butler and Kaja Silverman in order to state, on the one hand, an onto-epistemological turn that understands the body as the effect of social norms and, on the other, an ethical and political reflection about the levels of violent exposure that suffer those bodies that are excluded from the cultural frames that make a life livable. The concave mirror-as a possibility for other alternative ways of representing the body-is postulated as an alternative to the hegemonic ways in which the representation operates in the configuration of the body as a totality and unity: those that theory links to the flat mirror.
\end{abstract}

Keywords: body; violence; representation; precariousness; vulnerability 
EL PRESENTE ARTículo se propone reflexionar sobre el problema de la violencia que toma como objeto y escenario al cuerpo. Para ello se problematiza el abordaje sobre el cuerpo que postula Adriana Cavarero al indagar por los modos contemporáneos de la violencia. Desde su punto de vista cobra pregnancia el modo en que la violencia desarticula la materialidad del cuerpo, pero no se interrogan los procesos discursivos que participan en la producción del cuerpo mismo. Este giro, que nos conduce hacia una ontología política del cuerpo, nos enfrenta con la necesidad de preguntarnos por el modo normativo en que se articula la representación del cuerpo en el pensamiento moderno. Esta indagación no solo se sostiene en un interés teórico y epistemológico, sino en una preocupación ético-política. Tal preocupación se manifiesta a lo largo de la producción filosófica de Judith Butler, quien intenta exponer la violencia que ejercen las normas sociales al producir los criterios que delimitan aquello que se considera como vida humana y aquello que no.

En su conjunto de ensayos, reunidos bajo el título Marcos de guerra, Judith Butler (2010) señala que "si ciertas vidas no se califican como vidas o, desde el principio, no son concebibles como vidas dentro de ciertos marcos epistemológicos, tales vidas nunca se considerarán vividas ni perdidas en el sentido pleno de ambas palabras" (p. 13). De este modo la autora sitúa el problema de la violencia en una dimensión epistemológica. Esta involucra esquemas sociales de inteligibilidad que condicionan y producen las normas de reconocibilidad que preparan el camino al reconocimiento. En aquellas franjas poblacionales que permanecen fuera de tales esquemas, nos dice Butler, la vida no cuenta como vida. Es así como la vulnerabilidad corporal de cierto conjunto de personas se redobla mediante la potenciación de la violencia que la ininteligibilidad social del desamparo de la norma produce. Entonces aquellos cuerpos que se alejan de los términos normativos se encuentran expuestos a daño. Pues, parafraseando a Butler, podemos afirmar que todo cuerpo debe conformarse a ciertas concepciones de lo que es el cuerpo para ser inteligible como cuerpo.

En primer lugar, el artículo expone el modo en que las ideas de Adriana Cavarero (2009) involucran al cuerpo en la delimitación de los modos actuales de violencia. La autora se centra en una forma de violencia extrema que rompela unicidad 
del cuerpo, fragmentándolo en pedazos, de modo que "ofende a la dignidad ontológica que la figura humana posee” (Cavarero, 2009, p. 25). Como estrategia para cuestionar la idea de una figura humana contenida ontológicamente en la unicidad del cuerpo, se apela a un espectro de autores que ofrecen argumentos para postular al cuerpo como efecto de un proceso que involucra la dimensión normativa, social y política. Tal es el caso de Jacques Lacan, de Judith Butler y de Kaja Silverman. Asimismo la figura de Medusa, a la que acude la propia Cavarero como un ejemplo paradigmático de la violencia que fragmenta al cuerpo, nos permite avanzar en un profundo cuestionamiento sobre el carácter especular de la representación a partir de la cual se conforma el cuerpo idealmente normado.

Si Lacan sitúa en el estadio del espejo la configuración de la identidad ligada a la identificación con una imagen reflejada que imprime unidad a la vivencia fragmentaria, entonces esa autoimagen es producto de un complejo proceso de incorporación que no puede entenderse sin una dimensión social que impone la unidad como ideal normativo. Pensadoras del campo del feminismo como Luce Irigaray (2007) y Hélène Cixous (1995) también acuden a la metáfora del espejo, para mostrar la corporalidad de la mujer como lo otro del sujeto masculino. Desde aquí Teresa de Lauretis (1992) lanza interrogantes que resultan de interés para el recorrido del presente artículo: “iqué sucede [...] cuando las mujeres se miran en el escudo de Perseo mientras la Medusa está siendo degollada?” (p. 17). En atención a esta pregunta se presta especial atención al carácter cóncavo del escudo de Perseo en el que Medusa se refleja. Allí se sitúa una alternativa a la representación moderna articulada bajo la idea de reflejo de la realidad que toma como modelo el espejo plano. La posibilidad de concebir nuevos imaginarios representacionales a la hora de pensar el cuerpo permite, por un lado, situar el carácter político del proceso que idealiza ciertos cuerpos en detrimento de otros, y, por otro lado, llamar a la necesidad de transformar los marcos normativos que producen vidas que valen la pena ser vividas y otras que ni siquiera cuentan como vidas. Aquí se intenta argumentar que el cuerpo es un primer bastión donde el poder opera en la producción de vida y muerte.

Adriana Cavarero: el horror ante la fragmentación del cuerpo

Bajo un profundo cuestionamiento del lenguaje bélico utilizado para significar las escenas de masacres terroristas contemporáneas, Adriana Cavarero 
(2009) se interroga sobre la inermidad de las víctimas. Desde allí destaca el horror como carácter central de, y como vía para reflexionar sobre, los modos actuales de la violencia. La autora señala que la violencia prolifera con una maleabilidad camaleónica capaz de asumir formas inauditas, e invade la esfera social usufructuando las zonas oscuras a las que la lengua contemporánea aún no puede iluminar - por la dificultad de forjar nominaciones plausibles-. La vaguedad y la ambigüedad de vocablos, como guerra o terrorismo, advierte Cavarero, no se cuestionan. Es así como la falta de definiciones claras se combina con el enmascaramiento de los usos de la lengua a la hora de dar cuenta de las formas más crueles de violencia sobre el inerme.

El examen etimológico que pone en marcha Cavarero no encuentra al terror en el corazón de estos modos muy específicos de violencia-caracterizados por el despedazamiento, la carnicería y la fragmentación de aquellos signos que conservan la humanidad en la totalidad e integridad del cuerpo singular-. La etimología de terror nos conduce al miedo en su dimensión física. Se trata del cuerpo que tiembla y huye. Su raíz latina en terreo y tresas ubica al terror como "lo que actúa de inmediato sobre el cuerpo, haciéndolo temblar y empujándolo a alejarse con la huida" (Cavarero, 2009, p. 20). Cavarero considera otra reacción física en su análisis: poner los pelos de punta, estado que encuentra su expresión latina con el verbo horreo. Es el horror, y no el terror, la manifestación corporal que a criterio de la autora resulta apropiada, pues implica congelarse -el griego phrissō y el latín frigus circulan en el espectro etimológico al que apela Cavarero-. Cuando del horror se trata, nos dice Cavarero (2009),

no hay movimientos instintivos de huida para sobrevivir ni, mucho menos, el desorden contagioso del pánico. [...] El movimiento aquí se bloquea en la parálisis total y atañe a cada uno, uno a uno. Invadido por el asco frente a una forma de violencia que se muestra más inaceptable que la muerte, el cuerpo reacciona agarrotándose y erizando los pelos (p. 24).

El estado de parálisis que Cavarero (2009) enfatiza como síntomas corpóreos que caracterizan la fisica del horror, refieren a una instintiva repulsión hacia una forma de violencia cuyo sentido último no es matar, sino desarticular "la condición humana misma en cuanto encarnada en la singularidad de cuerpos vulnerables" (p. 25). A criterio de Cavarero, este cometido se logra cuando la violencia destruye "la unicidad del cuerpo y se ensaña en su constitutiva vulnerabilidad" (p. 25). 
En este contexto, Cavarero avanza hacia la innovación lingüística y propone el vocablo horrorismo. Formas de violencia cuyo despliegue lleva consigo el ensañamiento de atacar el cuerpo desprendiendo, por ejemplo, de forma limpia la cabeza. La escena propia del horrorismo es la masacre -carnicería donde la distribución de restos es tal que se vuelve imposible recomponer partes para reconocer y contabilizar los cuerpos de las víctimas-. De este modo Cavarero (2009) sitúa la confusión de miembros de los cuerpos deshechos -que, así, pierden su individualidad- en la base de una violencia que desarticula la figura humana y, consecuentemente, su "dignidad ontológica".

Ofender la dignidad ontológica de la víctima implica, entonces, deshumanizar. Así, el horror radica en todo acto que golpea al humano en cuanto humano y destruye la unidad simbólica del cuerpo. Otro componente nodal del horror, tal como lo tematiza Cavarero, radica en el carácter inerme de la víctima. Todo cuerpo, nos dice la autora, es vulnerable puesto que siempre está abierto a la herida del otro. Y este es el principio fundamental que la inermidad redobla cuando la violencia se ejerce unilateralmente sobre quien está desvalido e indefenso. Cavarero (2009) señala que "cuando se la entiende en términos corpóreos, la unicidad que caracteriza el estatus ontológico de los humanos es, ciertamente, también una constitutiva vulnerabilidad" (p. 44). Y cuando la vulnerabilidad, propia del ser corpóreo, se expone de tal modo que resulta imposible defenderse de la herida debido a que su singularidad corpórea no prevé reciprocidad, es entonces cuando la inermidad invoca el horror.

Cavarero (2009) encuentra en los relatos de Homero un ejemplo de la masacre: "las tripas que rebosan del vientre, la cabeza cortada que vuela lejos con su yelmo, la médula que brota de las vértebras" (p. 29). Claramente la clave es la pérdida de la unidad del cuerpo cuando del horror se trata. En tal caso los efectos que la violencia persigue son "la descomposición del cuerpo herido y, después, del cadáver, su apertura y desmembramiento" (p. 30). La unicidad corpórea tiene un sentido propio tal que, para Cavarero, el cuerpo muerto, aunque no la vida, aún conserva algo por ser arrebatado: la unicidad de su figura. Y no podría ser de otro modo, pues el horror solo irrumpe con el efecto de desfiguración que destruye al viviente como cuerpo singular. El horror se materializa cuando las partes, incluso el interior, traspasa, en múltiples direcciones, los límites que contornean las fronteras del cuerpo, es decir mediante todo "acto violento que lo deforma" (Cavarero, 2009, p. 31). 
Jacques Lacan: la unidad del cuerpo, un punto de llegada

La perspectiva de Adriana Cavarero (2009) destaca el carácter repugnante del horror que se desprende del "desmembramiento del cuerpo, que cancela la unicidad reduciéndolo a carne sin unidad de figura alguna” (p. 53). Su incansable insistencia en asignar el estatuto de crimen ontológico a toda violencia que, aún yendo más allá de la muerte, asesina la unicidad del cuerpo, conduce a Cavarero a prestar especial atención a la cabeza cortada de Medusa, en tanto ofensa paradigmática a la unicidad corpórea de toda vida. Es así como Medusa constituye el rostro mítico del horror en la mitología griega.

Cavarero (2009) nos dice: "Medusa es una cabeza cortada. Ante todo, repugna al cuerpo su desmembramiento, la violencia que lo deshace y lo desfigura. El ser humano, en cuanto ser encarnado, es aquí ofendido en la dignidad ontológica de su ser cuerpo" (p. 24, énfasis añadido). Cavarero sitúa el problema en la materialidad de un cuerpo que se deshace y se desfigura. Este ser cuerpo supone, entonces, una unicidad constitutiva inscripta en una configuración original y ontológicamente sustancial. En este punto es preciso interrogarnos -ahora sí, echando mano de una serie de intelectuales que se adscriben a otra perspectiva onto-epistemológica- acerca de los procesos simbólicos y normativos que hacen y figuran el ser cuerpo -como punto de llegada y no de partida- bajo la violencia normativa de la unicidad como ideal formal naturalizado (Butler, 1993).

Sin sospecharlo, la misma Cavarero (2009) sugiere una potente aproximación teórica que permite zanjar la cuestión -bajo los términos que aquí resultan de interés-, al mencionar:

Animados por los juegos especulares que pertenecen a la leyenda de Perseo, a menudo se supone que Medusa representa la inmirabilidad de la propia muerte. Más allá de ser verdad en el plano empírico, la tesis es fácil de argumentar en base a algunos elementos del mito; entre éstos: la petrificación del cuerpo que evoca la rigidez del cadáver y el espejo que alude a la identificación del sí mismo en la muerte del otro (p. 24).

Jacques Lacan (2009a) ofrece elementos teóricos que permiten pensar el modo en que el sujeto articula su identidad a partir de la totalidad y unicidad del cuerpo como efecto de un proceso muy específico que involucra la dimensión de la mirada 
en vinculación a juegos especulares, denominado estadio del espejo. Este involucra la reacción del niño ante el reflejo presentado en el espejo simplemente como una imagen tomada como realidad. Solo cuando deja de tratar la imagen como un objeto real, y ya no intenta tomar posesión de aquello que yace en el espejo, el niño asume aquello como imagen propia. Aquí la identificación comienza a tener lugar y emerge el yo -sede de la identidad del sujeto-. La identificación con la imagen especular supone que el yo se forma a partir de una dialéctica donde la imagen se postula como otra, negada y luego afirmada como yo. Podría decirse que es un proceso de incorporación de la alteridad cuyo resultado es la producción del yo.

Todo parece indicar que las primeras experiencias del niño permanecen inmersas en sensaciones corporales caóticas que transcurren en la imposibilidad de distinguir interior/exterior, yo/otro. Lacan intenta comprender la relevancia que guarda el reconocimiento que el niño realiza de sí mismo en la imagen especular, en tanto imprime forma a la experiencia pre-lingüística, caótica e indiferenciada. La imagen en el espejo ofrece un primer momento de reconocimiento, donde el yo se constituye en un giro delineado por el trayecto escópico que supone verse a sí mismo viendo. Así, la imagen en el espejo configura la base imaginaria -registro donde Lacan ubica las identificaciones- de coherencia del yo y unidad del cuerpo como dos caras de la misma moneda. El trayecto de la identificación toma como soporte a la imagen, y localiza la existencia del yo allí donde no estaba. La relación interior/exterior se trastoca. La imagen ideal, nítida y clara del espejo es interiorizada vía identificación, confiere realidad al yo y se instala como modelo para el $y o$, en inextricable relación con el ideal del cuerpo como totalidad.

Identificarse es tomar como propia la existencia localizada inicialmente en un espacio fuera de sí. Entrampa al sujeto en un intento constante por mantener de manera invariable la identidad y la sustancialidad del yo. El sujeto llega a tener conciencia de sí mismo configurando una identidad cuyos límites, contorneados en la imagen, no deben ser cruzados. Se trata de una verdad incuestionable del sí mismo que debe ser defendida, ya que, en última instancia y desde el punto de vista del sujeto, lo que está en juego es la propia existencia. Claramente, la experiencia ante el espejo instala una fantasía psíquica fundamental de autonomía (Martínez, 2013).

Entonces, el estadio del espejo debe ser entendido como un momento clave, pues allí se constituye el yo en tanto unidad que sutura un cuerpo en fragmentos. 
La complejidad de esta propuesta teórica radica en que esta operación no solo inaugura prospectivamente la unicidad del cuerpo que la imagen en el espejo refleja -sobre la que cabalga la emergencia del yo-, sino que también da inicio retroactivamente a un cuerpo en pedazos -y ahora arrojado al oscuro reino subyacente de lo inconsciente, donde la conciencia atenta no puede llegar. En sentido estricto se trata de un momento de autoengaño en el que el circuito de la mirada cae presa de una imagen ilusoria. Tanto la existencia de aquella instancia capaz de forjar un saber acerca de sí misma, como su despliegue temporal hacia el futuro y el pasado se sostienen en una ilusión (Woodward, 1983).

El carácter ilusorio del estadio del espejo nos permite afirmar el estatuto imaginario de la totalidad y completud que la identificación con la imagen fuera de sí -en la superficie del espejo- otorga al registro del cuerpo. Se trata de una imagen que el espejo proyecta sobre los pedazos corporales, ahora reunidos bajo la totalidad que el límite continuo de la Gestalt encierra. Según Lacan (2009a), "el punto importante es que [el ideal formado en el estadio del espejo] sitúa la instancia del yo [...] en una línea de ficción" (p. 100). Por tanto, junto a la ficcionalidad emerge una dinámica temporal compleja -no reductible a la cronología- que reúne, a la vez, anticipación y retroacción. Esta particular temporalidad instala el yo mediante la anticipación de aquello en lo que se convertirá -un yo unificado y coherente-, y, en la misma operación, el yo se vuelve patrón de medida que otorga existencia, retroactivamente, a lo que era antes. Entonces, la imagen corporal anticipada como totalidad produce la fantasía retroactiva del cuerpo en pedazos.

Lo que ocurre así en la etapa del espejo es lo que gramaticalmente Lacan denomina como futuro anterior. Nos dice: "mi historia no es el pretérito-definido de lo que fue, puesto que ya no es, ni siquiera el perfecto de lo que ha sido en lo que yo soy, sino el futuro anterior de lo que yo habré sido para lo que estoy llegando a ser" (Lacan, 2009b, p. 288).

La temporalidad en la que se libra la historia subjetiva es un entrecruzamiento entre futuros anteriores y pasados posteriores, entrecruzamiento que elimina doblemente la realidad presente por la acción combinada de la anticipación y la retroacción (Gallop, 1983). Lacan (1953) menciona respecto al yo:

Ilusión de unidad en la que un ser humano busca el autodominio y que bordea siempre un constante peligro; deslizarse nuevamente hacia el caos del que 
partió. Ilusión que pende sobre el abismo de una vertiginosa aquiescencia en la que quizá pueda verse la esencia misma de la angustia (p. 15).

Entonces, el cuerpo como totalidad es una ilusión hecha con espejos, un ideal proyectado que construye yo sobre un terreno hueco. El autodominio que se ubica en la base del yo es el producto de una ilusión anticipatoria, y la imagen especular con la que el sujeto se identifica inunda al yo con la imposibilidad de coincidir consigo mismo. En este contexto, el autodominio es una pretensión cuya cabal concreción queda infinitamente diferida. Como se ha señalado, ese momento también instala, de algún modo, la significación del pasado. Por lo tanto la posibilidad de apelar a sucesos previos como fuente de comprensión y como conjunto de determinaciones de yo también queda infinitamente diferida.

Tal como sugiere Lacan, la angustia para representar el riesgo yoico de deslizarse nuevamente hacia el caos solo puede ser experimentada una vez que el yo ha cobrado existencia - una vez producida la ilusión de unidad-. El estadio del espejo es el inicio de una vertiginosa aquiescencia, fugaz momento de júbilo que inmediatamente convoca a la angustia. Se trata de un drama: un breve momento de gloria bajo la condena angustiosa de la pérdida que amenaza. La operación especular origina, al mismo tiempo, la totalidad ideal y el fragmento espectral amenazante. El yo, entonces, implica un movimiento de huida del reconocimiento horroroso de su desnudez. No es posible asumir anticipadamente un cuerpo totalizado sin la irrupción retroactiva de la posibilidad de su desmoronamiento en fragmentos. Según Lacan (2009a),

el estadio del espejo es un drama cuyo empuje interno se precipita de la insuficiencia a la anticipación; y que para el sujeto, presa de la ilusión de la identificación espacial, maquina las fantasías que se suceden desde una imagen fragmentada del cuerpo hasta una forma que llamaremos ortopédica de su totalidad -y hasta la armadura por fin asumida de una identidad alienante(pp. 102-103).

El trayecto del sujeto está delineado: desde la insuficiencia (cuerpo en pedazos) pasando por la anticipación (forma ortopédica), hasta llegar a una armadura rígida de la identidad alienante. Pero, nuevamente, esta cronología debe ser examinada. Cuando Lacan menciona la existencia de un empuje que va desde la insuficiencia hacia la anticipación debe entenderse que aquella insuficiencia solo 
cobra forma desde la perspectiva de la anticipación (Linder, 1993). La imagen del cuerpo en trozos y pedazos se produce retroactivamente desde la imagen reflejada en el espejo, anticipada como forma ortopédica de totalidad.

El cuerpo puede definirse retroactivamente como insuficiente o fragmentario, por lo que el segundo término precede al primero: la anticipación de la totalidad inaugura el fragmento con posterioridad. Ahora bien, una sucesión temporal donde el segundo término puede preceder al primero, ¿no anula, acaso, la idea de finalidad o punto de llegada teleológicamente instalado por la pretensión cronológica linealmente determinada?

Entonces, si la anticipación está siempre enredada con la retroacción, ęla conclusión inevitable es la armadura rígida de una identidad alienante? La sucesión temporal entendida en términos de una cronología irreversible instala una progresión lineal que conduce al drama de la identidad rígida anudada a un cuerpo entendido como totalidad. Pero dado el efecto de la retroacción, se podría decir también que es la rigidez la que produce una cronología irreversible. En el drama lacaniano, el yo se vuelve rígido, como una armadura dolorosa y pesada que la psique soporta como precio por la obtención de reconocimiento social (Lynch, 2008).

Judith Butler: imaginarios morfológicos y esquemas normativos

Judith Butler (2007) SeÑala que "no se puede aludir a un cuerpo que no haya sido desde siempre interpretado mediante significados culturales” (p. 57); en efecto, parece imposible referir al cuerpo sin recurrir a un discurso normativo que lo interprete y, entonces, le otorgue forma. La autora propone una alternativa para socavar los esquemas hegemónicos a partir de los cuales se decodifican los cuerpos. Como operación de rescate destinada a arrebatar el cuerpo de un campo delimitado a partir de fundamentos naturales, la autora instala la pregunta: ¿Qué es lo que constituye, en última instancia, una parte corporal?

La captura crítica de aquello que percibimos como la carne real (Kirby, 2011) supone el análisis de procesos culturales que comandan la materialización de los cuerpos. En otras palabras, Butler se propone un cambio de perspectiva desde la cual se torna visible el código cultural oculto tras la apariencia de la materialidad de la existencia bruta. El nuevo punto de mira solo se logra cuando el espectador ha agudizado su capacidad de extrañamiento a un punto tal que es posible 
desarticular la densa trama de los regímenes sociales de significación que invisten fantasmáticamente los cuerpos. En este contexto conceptual construido por Butler, el cuerpo, en su sentido anatómico, no constituye un referente original. El cuerpo adquiere existencia cuando es contorneado por límites, no naturales, que imponen una morfología, tampoco natural (Butler, 1989).

En Cuerpos que importan, Butler (2008) recurre a Freud y a Lacan para exponer la ambivalencia, implícita en las operaciones de escritura, con la que se enfrentan los autores en algunos de sus textos fundamentales, con el objetivo de vislumbrar nuevos imaginarios morfológicos posibles. Para ello apela a Introducción del narcisismo, en el cual Freud (1914/1979) vincula la autoinvestidura libidinal con el dolor y, finalmente, con la hipocondría. Estas vinculaciones le permiten a Butler fijar como epicentro las experiencias corporales del narcisismo para instalar el desplazamiento que permite afirmar que no hay cuerpo antes de tales experiencias. Tanto el dolor como la hipocondría vienen a dar cuenta del depósito de líbido sobre una parte del cuerpo, la que no existe para la conciencia antes de tal carga libidinal (Besetzung). Siguiendo esta línea, todo parece indicar que no es tan sencillo establecer una frontera entre heridas físicas y heridas imaginarias. Dicho en otras palabras, la parte corporal y la partición fantasmática que la torna cognoscible bajo la conciencia son indisolubles.

La interpretación de Butler sitúa el modo en que Freud, a través de un giro textual, vincula las autoinvestiduras libidinales con la hipocondría, para dar paso al carácter indisoluble entre las heridas físicas y las heridas imaginarias. Según Freud, la hipocondría deposita la libido sobre una parte del cuerpo, y ese mismo movimiento de investidura da origen psíquico a la parte corporal investida. Es decir que dicha parte del cuerpo cobra inteligibilidad a partir de tal operación libidinal. Dolor e hipocondría, entonces, se vinculan en el autodescubrimiento corporal, siguiendo la denominación de Butler.

A partir de aquí, la autora postula la construcción imaginaria de las partes corporales. Así afirma el carácter indisoluble del cuerpo físico y la psique. Según las afirmaciones de Freud en El yo y el ello (1923/1979), es posible vincular la constitución del yo con las sensaciones corporales. Si, a criterio de Freud, podemos entender el surgimiento del yo como la proyección mental de la superficie del cuerpo y, de este modo, el cuerpo mismo representa las superficies del aparato mental, entonces como sugiere Butler, la inscripción psíquica correspondiente a 
la idea de una parte corporal emerge simultáneamente cuando dicha parte del cuerpo se torna fenomenológicamente accesible, lo que confirma la imposibilidad de aislar claramente la parte del cuerpo y la fantasmatización que le otorga su carácter de experiencia psíquica.

Si aceptamos el razonamiento de Butler, el acceso a la anatomía depende y coincide con un esquema imaginario. Por otra parte negar la existencia de ese esquema implica negar la existencia del yo, instancia de centralización temporal de la experiencia. Ahora bien, ¿queda algún resto -ya sea en términos materiales o representacionales- que podamos llamar cuerpo más allá de los límites de tal esquematización? Para Butler (2008), los contornos del cuerpo son sitios que vacilan entre lo psíquico y lo material. La materialidad del cuerpo, entonces, no debe pensarse como unilateralmente originada por la psique. Sin caer en un idealismo insostenible, Butler no niega que el carácter material del cuerpo depende de las esferas anátomo-fisiológicas y biológicas; sin embargo, propone pensar qué matrices interpretativas condicionan, permiten y limitan tal materialidad (Campagnoli, 2013; Martínez, 2015). Luego de plantear las consecuencias que tiene la teoría del narcisismo en la formación del yo corporal, Butler retoma las conceptualizaciones lacanianas en torno al estadio del espejo (Lacan, 2009a) que reescriben la teoría freudiana del narcisismo (Freud, 1914/1979). Allí Butler lee una concepción de morfología en relación con la idealización o ficción del cuerpo como totalidad y locus de control. Esta línea que establece la proyección narcisista e idealizante en la constitución de la morfología del cuerpo permite subvertir la idea de la existencia de un yo anterior a las identificaciones. Por el contrario, las identificaciones preceden al yo y la relación identificatoria con la imagen establece el yo. En síntesis, el yo no es una sustancia idéntica a sí misma, sino que es una historia sedimentada de relaciones imaginarias que sitúan el centro del yo fuera del yo. Es la imago externalizada que confiere y produce los contornos corporales. El espejo no se limita a reflejar un yo preexistente, sino que suministra el marco, la frontera, la delineación espacial para que pueda elaborarse proyectivamente el yo mismo. Por otra parte, la imagen especular que ve el niño es una representación imaginaria que produce al niño mismo, quien, a su vez, confiere integridad y coherencia a su propio cuerpo.

Como fuere, queda claro que para Butler $(2007,2008)$ el cuerpo, como efecto, se materializa cuando asume una morphế. De aquí en más, para Butler 
es posible reescribir el imaginario corporal. Butler advierte que la formulación lacaniana sobre la identificación depura, al menos en este punto, elementos esencialistas presentes en la teoría freudiana de la formación del yo. Butler se aleja de toda concepción que inscribe la constitución del yo -por lo tanto, de la identidad- sobre la base de una esencia o fundamento universal. La idea de que el yo se conforma a través de la identificación con la imagen efímera que refleja el espejo adviene entonces como un recurso conceptual del que echar mano.

Como Butler demuestra, siguiendo a Freud, el advenimiento del yo es correlativo a la proyección de una superficie corporal. Situar la identificación con la imagen en la base del yo, como lo hace Lacan, involucra la dimensión corporal. El yo es, fundamentalmente, un yo corporal, y si afirmamos que no existe un yo previo a las identificaciones, entonces es posible afirmar que el yo y la morfología del cuerpo responden a un mismo proceso de formación. Los sutiles nudos normativos que unen las identidades con las formas corporales generan la ilusión de continuidad. En este contexto, lejos de lo que nos sugiere la conocida afirmación "la anatomía es destino" (Freud, 1924/1979, p. 185), yo y cuerpo son dos dimensiones estrechamente interconectadas, constituidas mediante el mismo proceso identificatorio.

Ahora bien, si los límites corporales se contornean en la constitución misma del yo mediante el poder regulativo de esquemas normativos, y si tales morfologías corporales pueden entenderse como efectos impuestos y materializados del poder regulador, entonces reelaborar los términos de tales esquemas normativos sugiere la posibilidad de proyecciones variadas y de concebir imaginarios alternativos. Después de todo, como aclara Butler (2008), las prohibiciones no siempre implican eficacia en la producción de cuerpos dóciles que acaten plenamente el ideal social, por ello es posible, a criterio de la autora, delinear superficies del cuerpo que no signifiquen las pautas normativas convencionales.

Como fuere, todo parece indicar que la constitución del yo, y su cuerpo concomitante -aunque bien podría enunciarse como la constitución del cuerpo, y su yo concomitante- responde a un proceso mediante el cual las normas sociales hunden sus raíces en las subjetividades. En algún sentido podríamos afirmar que la identificación, cuyos trayectos normativos se encuentran regulados por esquemas a partir de los cuales interpretamos las buenas formas corporales, conforman o materializan eso que llamamos cuerpo (Butler, 1999). 
Kaja Silverman: la pantalla y la identificación ex-corporativa

Kaja Silverman (1996) enfatiza el modo en que el estadio del espejo inaugura la diferencia y vinculación entre el yo emergente interno y la realidad externa -entre el Innenwelt y el Umwelt-, por lo tanto "la imagen especular parece ser el umbral del mundo visible" (Lacan, 2009a, p. 101). El espejo mismo provoca el reconocimiento de la alteridad como medio necesario para identificarse con la imagen que ve. La autora se centra en la vertiente del pensamiento lacaniano en torno a la imagen que incorpora lo simbólico como partícipe en la conformación visual de diversos códigos no ajenos a la identificación subjetiva y al reconocimiento social. Bajo la noción de pantalla, Lacan denota algo más que la cuadrícula de imágenes a través de la cual un sujeto lee una sociedad. La función de la pantalla excede la mediación con lo social. Más importante aún: filtra lo real, por tanto protege al sujeto de la mirada del mundo, capta la luz pulsátil, brillante y ostentosa (Lacan, 1987) - y la domestica en imágenes. Lacan sugiere que la pantalla cumple la función de domesticación de la mirada. Así, tenemos acceso a lo simbólico no solo en las articulaciones del lenguaje sino en las imágenes de la pantalla que moderan y manipulan la mirada. La pantalla permite contemplar la imagen, de lo contrario lo real nos cegaría con su radiación (Silverman, 1993).

Lejos de operar a modo de un velo denso que oscurece la realidad, o como una ilusión que confunde, la pantalla constituye una protección necesaria sin la cual estamos a merced de lo real. La lógica normativa somete lo horroroso presente en lo real. La completud de la imagen resulta una protección contra la desestructuración de los fragmentos que amenazan con disolver los fundamentos simbólicos en los que se fundamenta el sujeto. La integración imaginaria del cuerpo lograda en el estadio del espejo proyecta una etapa previa lejana a una plenitud fenomenológica, y más bien cercana a un temible cuerpo en pedazos que se debe evitar a toda costa. La pantalla opera proyectando lo real como fragmentario, amorfo y horroroso. Al respecto Joan Copjec (1989) señala que más allá de la red significante, más allá del campo visual, no hay absolutamente nada. El velo de la representación no oculta nada. Más bien la representación coloca una pantalla de significantes frente a algo subyacente. No se trata de un error que el sujeto puede deshacer. Se trata de la amenaza de lo fragmentario que la opacidad 
del lenguaje ficcionalmente oculta para preservar libre de amenazas los límites corporales. En su contexto conceptual, Lacan no puede imaginar formas del arte que transgredan la pantalla para transformar radicalmente la amenaza real de lo fragmentario. ¿Y cómo podría, si lo real lacaniano -que la pantalla se empeña en ocultar- constituye un espacio negativo de significación, exterior a lo simbólico, donde no transcurre modo posible de subjetividad?

Como fuere, las ambiciones transgresoras de Kaja Silverman (Hüser \& Silverman, 1997) parecen proponer un desgarro de la pantalla, un sondeo de lo real -que en sus propuestas parece posible-. La autora propone la identificación con aquellos a quienes el orden social decreta como inaceptables. Sin embargo la gestión de la dirección de nuestras identificaciones no es un acto voluntario, la identificación arraiga nuestra existencia muy profundamente -después de todo estas ideas sugieren un centro ontológico ausente, por tanto el sujeto no es más allá de sus identificaciones y las direcciones hacia las que estas se dirigen-. La exigencia ética de identificarnos con referentes identificatorios que se encuentren más allá del abismo de la diferencia -que este propio recorrido identificatorio instala como corolario de la ficción de un sujeto idéntico a sí mismo- tiene consecuencias tanto para la estructura del yo como para la imagen corporal siempre mediada por la pantalla-. Por lo tanto, la articulación del cuerpo no permanece ajena a una imagen hegemónica con precisas exigencias normativas que comandan su representabilidad (Felman, 1988). La identificación participa en la conformación de esta imagen, y del sujeto mismo. Silverman detecta que en el pensamiento freudiano la identificación se despliega a través de un proceso introyectivo (Fuss, 1995). Tan es así que el otro es, metafóricamente, consumido o devorado, y es así como forma parte del yo. Esta dinámica in-corporativa de la identificación refuerza y sostiene la existencia del yo en términos de identidad/ mismidad, donde la imagen que se proyecta sobre, y que con-forma, la superficie del cuerpo, no es ajena a los marcos normativos hegemónicos. Es así como Silverman nos invita a concebir una identificación ex-corporativa, heterotípica, donde el sujeto es capaz de entregarse a otro en un estado de fascinación, más allá de lo que su espectro de posibles identificatorios le habilita de antemano.

Este anudamiento entre el mecanismo psíquico de la identificación y un orden político-normativo -ya sugerido, aunque de otro modo, por Judith Butler (1997) - constituye la base del argumento ético de Silverman. Si tenemos en 
cuenta que un otro se torna objeto de identificación en función de un sistema de ideales, y consideramos, según Freud (1923/1979), que el yo es un residuo de identificaciones, entonces el yo corporal ${ }^{1}$ se forma en relación con las normas e ideales culturales. Invocando los trabajos de Paul Schilder (1923) y Henri Wallon (1975), Silverman (2000) reflexiona sobre la imagen y la apariencia del cuerpo humano en relación con las sensaciones físicas - experiencia corporal que Wallon denomina yo propioceptivo-. Esta experiencia fundamental del propio cuerpo adquiere relevancia en las ideas de Silverman, pues desde allí sugiere que nuestras posibilidades de identificarnos con otros están limitadas por el temor de perder nuestra integridad corporal.

Entonces, la experiencia de la imagen corporal está gobernada por ideales; normas corporales basadas en ideales que parten de la unicidad y la totalidad. Es la concepción freudiana de la psique como sistema de signos la que ofrece a Silverman (Hüser \& Silverman, 1997) una plataforma sólida en la que sostener sus argumentos psicoanalíticos en torno a la imagen y lo visual. Su idea de que la identificación implica una teoría de la representación encuentra sostén en conceptos lacanianos, tales como la mirada y la pantalla. Como ya lo hemos señalado, si la pantalla es un filtro cultural, esta mediación establece los términos ideales respecto a cómo debemos presentarnos ante los otros. El cuerpo no está exento. La totalidad constituye un ideal normativo fuerte que participa en la composición visual de un cuerpo. Al decir de Shoshana Felman (1988), en la superficie del espejo las ropas nuevas del emperador operan como una pantalla para la propia desnudez.

Finalmente, imaginarnos una mirada que evite la mediación de la pantalla, si es que esto es posible -y para Silverman lo es-, permite pensar el riesgo, o la posibilidad, de identificarnos con lo no ideal. Y es allí donde se ubica el compromiso radical con la otredad que Silverman postula como imperativo ético. La pantalla no solo traza las coordenadas sociales de lo ideal, también define lo abyecto, cuerpo incorrecto, en su tamaño, forma, color.

1 Señala Freud (1923/1979) que "el yo es ante todo [...] la proyección de una superficie" (p. 27). 
Una Medusa recobrada: alterar la representación

¿Qué Es aQuello QUE EleVA LA IMAGen DeSMembrada a un signo del horror (Cavarero, 2009)? Sabemos que aunque sus cabellos erizados y serpentinos le dan un aspecto monstruoso, su cabal peligrosidad reside en la mirada: su arma mortal. Sin embargo, desde las claves que brinda Cavarero lo que hace de Medusa símbolo de horror es la fragmentación que en ella se ha operado. Es el desmembramiento que la despoja de la dignidad ontológica de lo humano. A partir del recorrido trazado hasta el momento, es factible señalar que Medusa no reúne las disposiciones ideales que la norma requiere para trazar los límites -políticos- de lo humano.

Nos es conocido que Perseo consigue acercarse a Medusa sin mirarla a los ojos. Solo así fue posible arrebatarla por la cabellera y, con su espada afilada, cortar su cabeza. El acto de Perseo es heroico porque el rostro de Medusa petrifica a quien lo contempla. Existen muchas versiones del mito, pero a partir del siglo $\mathrm{V}$ cobra relevancia la superficie refractante del escudo que, haciendo las veces de espejo, se torna necesaria como medio que permite al héroe burlar la mirada de Medusa. Su imagen es detenida en ese mismo escudo -ahora constituido como amuleto apotropaico-, y así su mirada se fija en su égida conocida como Gorgóneion (Foster, 2003). El denominado gorgóneion -la imagen frontal de su rostro que ya aparece en el arte simbólico de los griegos y que perdura durante siglos- otorga a Medusa una existencia descorporeizada. Su cabeza se presenta en la simbología como representante metonímica de la totalidad, al menos si suponemos que allí falta un cuerpo en función del cual la cabeza es fragmento y su existencia descorporeizada. Es preciso recordar que la peligrosa mirada de Medusa continúa emulando su efecto luego de su decapitación.

$\mathrm{Si}$, junto a Claude Lévi-Strauss (1987), entendemos que todo mito constituye un entramado representacional, una narrativa que contribuye a hacer aprehensibles vacíos de sentido, es posible admitir, ahora junto a Hal Foster (2003), que Medusa tematiza el poder de la mirada y la potencia de la representación para controlarla. En otros términos, Medusa tematiza la abyección y el horror de lo in-forme, del fragmento, y de todo aquello que no reúne el ideal normativo que compone el ideal. En otras palabras, el mito de Medusa opera como el entramado de la pantalla que controla la mirada y, con ella, la dirección de las 
identificaciones que decantan en imaginarios morfológicos hegemónicos. Esta idea cobra fuerza si analizamos la transformación apotropaica que el mito expone, donde la amenaza de la mirada de Medusa se convierte en una especie de protección al formar parte, luego, del escudo que el héroe utiliza. El peligro, ahora dirigido contra el enemigo, se convierte en un medio de defensa. En suma, se trata de usos normativos de exponer el fragmento para, detrás de él, proteger el ideal de la totalidad y unicidad del cuerpo.

En un breve texto titulado La cabeza de Medusa (1922/1979), Freud considera esta imagen como símbolo de lo femenino. En la misma línea Adriana Cavarero advierte, al hablarnos de Medusa, que el horror tiene rostro de mujer. Nos dice que

cuando una mujer se presenta en la trampa del horror, la escena se hace más oscura y, aunque más desconcertante, paradójicamente más familiar. Aumenta la repugnancia y se potencia el efecto. Como si el horror, como ya sabía el mito, tuviese necesidad de lo femenino para revelar su auténtica raíz (Cavarero, 2009, p. 33).

Esta advertencia que liga la figura de Medusa con el horror y lo femenino permite leer la irrupción de la mediación simbólica de la pantalla (Lacan, 1973; Silverman, 1996). Y es esta misma mediación la que permanece presente en el escrito freudiano, pues allí se considera que el pelo serpenteante de Medusa constituye una figuración ambigua de los genitales femeninos, por tanto "el terror a la Medusa es entonces un terror a la castración” (Freud, 1922/1979, p. 270). Medusa petrifica al hombre ante el terror de la castración. Lo femenino asume aquí la carga de la no totalidad, la no completud. Bajo los términos normativos de Cavarero, podemos señalar el modo en que el psicoanálisis freudiano ha marcado simbólicamente los cuerpos femeninos como incompletos, por tanto sin acceso a la pretendida completud normativa que guarda las claves de la dignidad ontológica de lo humano. El mismo Freud afirma que el terror vinculado a la "horripilante cabeza decapitada de Medusa", por estar vinculado a "un terror a la castración” es, después de todo, "un terror asociado a una visión" (Freud, 1922/1979, p. 270). En sintonía con Cavarero, el terror al que refiere Freud no encuentra coordenadas normativas y, por tanto, se fundamenta en la herida de una totalidad y completud extradiscursiva que, incluso, coincide con lo masculino. 
Algunas producciones artísticas nos muestran a Perseo sujetando la cabeza de Medusa con una de sus manos, mientras con la otra sostiene una espada -tal es el caso de la pintura Perseo y Phineas (1597) de Annibale Carracci, y de las estatuas que petrifican a Perseo con la cabeza de Medusa, una de ellas realizada en bronce por Benvenuto Cellini (1545-1554), la otra realizada en mármol por Antonio Canova (1804-1806). Perseo mata a Medusa (1876), una estatua en mármol realizada por Laurent-Honoré Marqueste, escenifica a Perseo momentos antes de cortar la cabeza a su víctima. Allí Medusa yace con su cuerpo absolutamente derramado en la superficie del suelo. Perseo la sujeta por el conjunto de serpientes hasta elevarle la cabeza. La otra mano que sostiene la espada cerca de su cuerpo deja adivinar el movimiento que elevará la espada apuntando al cielo para dejarla caer y así fragmentar aquello que, según suponemos, es totalidad. En esta representación, el cuerpo casi desnudo de Perseo solo se vale de la forma filosa y prolongada de la espada que, de modo vertical y en dirección descendente, trazará el trayecto que comienza en la abstracción de la esfera celeste para culminar en la concreción de lo que se arrastra en el suelo, impartiendo justicia al retornar al monstruo al reino de los fragmentos.

Otro conjunto de producciones artísticas incorporan el escudo de Perseo como elemento fundamental en la escena. Peter Paul Rubens plasma con óleo y estilo barroco el instante en que Perseo libera a Andrómeda, en una pintura conocida bajo la leyenda Perseo liberando a Andrómeda (1608). Entre otras pinturas que comparten la centralidad del escudo podemos señalar obras tales como Perseo y Andrómeda (1607-1608) de Pier Francesco Mazzucchelli, la copia renacentista que Tiziano Vecellio (1554-1556) realiza con óleo sobre lienzo de la obra anónima conocida como Andrómeda y el dragón, el óleo de Charles Antoine Coypel (1694-1752) titulada Perseo rescata a Andrómeda, y la misma escena recobrada por Piero di Cosimo (1513), Paolo Veronese (1576-1578), en casi todas las versiones de Cavaliere d'Arpino (1593-1594, 1594-1595, 1594-1598), Pier Francesco Morazzone (1610), Peter Paul Rubens (1636, 1638), Guido Reni (1635), Pieter Pottel (1642), François Lemoyne (1723) y Charles André van Loo (1735-1740). Las versiones de Peter Paul Rubens (1639-1640), de Theodoor van Thulden (1606-1669) y de Pierre Mignard (1679) retratan la presencia del escudo en la escena de liberación de Andrómeda, aunque no en mano de Perseo, sino arrojado en el piso. 
En las versiones de Cavaliere d'Arpino (1620-1630) y de Annibale Carracci y Domenichino (1597), el escudo es reemplazado por la cabeza de Medusa, que es sujetada por las serpientes que aún conserva como cabellos. La cabeza de Medusa no guarda la misma función que el amurallamiento metálico del cuerpo de Perseo, pues no cuenta como elemento protector de la vulnerabilidad corporal, sino, más bien, como signo de que la totalidad, montada sobre el caballo alado que surca el cielo, se impone al fragmento -lo que en términos simbólicos supone un monumento al falogocentrismo aún mayor que empuñar una espada-. La mayor parte de las representaciones solo nos permite observar el escudo cuando el héroe es retratado en acción -la escena que lo involucra con Andrómeda es el caso más patente (Cristóbal, 1989)-.

Cuando de Medusa se trata, la escena de enfrentamiento no es figurada; las obras solo nos permiten ver la escena final donde Perseo sostiene en alto la cabeza de Medusa -sin cuerpo-. El escudo, una vez finalizada la batalla, es obviado. Probablemente la ausencia de escudo se deba a que, de estar presente, nos recordaría la vulnerabilidad del héroe. Sin embargo el escudo guarda una relevancia notable en el mito. Perseo mira a Medusa únicamente en el reflejo que ofrece la superficie del escudo. El juego especular de miradas, en vinculación con el problema de la representación, es central aquí. Solo mediante el reflejo en el escudo Perseo logra el desmembramiento y la fragmentación. Ahora bien, la imagen de Medusa en la superficie del escudo irrumpe en dos momentos diferentes. En primer lugar, se trata de la refracción como representación que modera la fuerza de su mirada. En segundo lugar, asistimos a la fijación de su cabeza cortada en el escudo del héroe. En la primera instancia, la representación detiene la mirada. En la segunda instancia la representación conserva y requiere su fuerza. Así, queda expuesta una doble captura y tratamiento que la pantalla representacional realiza respecto a la mirada. La modela y satura de categorías normativas al tiempo que usufructúa su potencia.

El hecho de que el poder de la mirada de Medusa continúa aún en el escudo a pesar de que su cabeza ya ha sido decapitada nos permite pensar la ausencia de ruptura absoluta entre la imagen y lo real. Más bien es posible establecer afinidades y modos subversivos de pasar de uno a otro. Todas las apariciones del escudo en las obras mencionadas recobran la misma estética y diseño. No se trata de un escudo aplanado. Su forma es circular y ovalada. Así, la imagen que 
se desprende del carácter cóncavo del escudo nos permite esbozar este traslado mediante algunas consideraciones. El brillo del metal pulido asegura el reflejo de imágenes y miradas - protagonistas en el desenlace que nos ofrece la narración del mito-. Sin embargo resulta de interés ensayar, en este punto, las distorsiones de las refracciones que las curvaturas de la forma del metal imponen a las imágenes que se deslizan en su superficie. Propongo resituar el escudo de Perseo como un elemento que interfiere con el modo en que normativamente se componen las imágenes bajo el ideal de totalidad. Nuevas líneas subversivas irrumpen cuando resituamos el fragmento -la cabeza de Medusa- como efecto de una operación identificatoria diferencial a la convencional y normativa que irrumpe a partir de un espejo cóncavo -el escudo de Perseo-.

¿Cómo debemos interpretar el reflejo del rostro de Medusa sobre una superficie cóncava? El fragmento ya no es ruptura de la totalidad. Si alteramos la economía representacional hegemónica, si logramos recomponer el carácter plano de la pantalla bajo la curvatura de lo cóncavo, la distorsión podría abandonar su valor referencial con respecto a lo auténtico y así la potencia del fragmento tendría su lugar. Después de todo, señala Jean-Pierre Vernant (2000), Medusa aparece como figura y máscara en Grecia desde el siglo VII. Este autor destaca una característica constante en todas sus representaciones: la vista frontal de su rostro que, según el autor, es una exposición que coexiste con una borrosidad monstruosa de todas las categorías. A menudo se la describe como joven y vieja, hermosa y fea, mortal e inmortal, celestial e infernal, tanto bestial como humana. Todo parece indicar que, detrás de las formas de representación de las que se vale la pantalla, insiste aquella mezcla inquietante entre el horror y el miedo a la confusión con la que el fragmento amenaza a la totalidad ideal. A diferencia de Cavarero, Vernant sitúa el carácter horroroso de Medusa en la confusión que produce en todas las categorías. La representación de su imagen no cesa de sugerir un retorno a lo informe e indistinto, y sus poderes, nos dice, son aquellos del más allá en su forma radicalmente inédita, tras la cual amenaza la muerte, la nada.

Del mismo modo, Lacan (2008) señala que la figura de Medusa configura un objeto ansiógeno. Pues su cabeza caótica es, nos dice, la revelación de aquello hacia lo que no podemos penetrar. En otros términos, sugiere un real sin mediación, donde todas las diferencias se confunden o, aún, ni siquiera poseen forma. 
Entonces, Medusa es una representación simbólica que -inesperadamente para la economía simbólica hegemónica- expone lo real como un otro radical al orden simbólico. Digámoslo claramente, la cabeza de Medusa interpretada como fragmento provoca horror -cuando el horror refiere a la pérdida de una imagen de unicidad y completud en la que reposa la ontología de lo humano- solo bajo los términos de una economía simbólica que gesta tales ideales. Lacan (2009a), Butler (2008) y Silverman (1996) nos permiten pensar cómo el reflejo del espejo plano adviene no solo como metáfora de los modos hegemónicos en que se gestan las representaciones convencionales, sino, también, como medio en que las identificaciones se deslizan articulando al sujeto en torno a estos modos de representabilidad. El espectro de ideas de estos intelectuales también sugiere que no existe emergencia del sujeto si no es abrazando una imagen del cuerpo -ahora ya sabemos que esta no se forja sin la pantalla- en la que anclar las claves y verdades de su existencia.

Cavarero (2009) sostiene que la cabeza de Medusa sufre una duplicación en los juegos especulares:

[...] más que representar lo inhumano en cuanto Otro [...], Medusa alude a un humano que, en cuanto desfigurado en su mismo ser, contempla el acto inaudito de su deshumanización. [...] La cabeza cortada es el símbolo de lo que la violencia extrema ha escogido por objeto (p. 35).

Si tomamos como referencia la imagen reflejada en una superficie cóncava podemos sostener la posibilidad de articular otros modos de representabilidad. La producción de una resignificación radical de los términos normativos y de los marcos hegemónicos (Butler, 2007) que componen los términos convencionales en que la representación se libra, nos conduce a la posibilidad de reinterpretar esta lectura de Cavarero. En el reflejo de la superficie cóncava Perseo recupera el fragmento tras la totalidad ilusoria. Como hemos visto, la cabeza de Medusa continúa emulando el poder de la mirada petrificadora. Tal cualidad no requiere

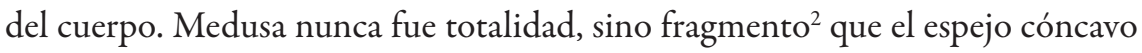

2 No es del todo adecuado nominarla como fragmento, pues es una categoría subsidiaria a la economía de lo Uno y del Todo, pero aludimos a una reivindicación de otras fronteras corporales alternativas que cuestionen el cuerpo y sus límites en un nivel ontológico y epistemológico. 
produce en una temporalidad compleja. Lacan ya nos ha permitido ver cómo el fragmento ya amenaza en los bordes de la superficie del espejo plano.

$\mathrm{Al}$ respecto, el feminismo ha hecho sus aportes. En la línea del feminismo de la diferencia -en la cual la propia Cavarero $(1995,2014)$ se enfila- Luce Irigaray (2007) introduce la problemática del espejo. Afirma que el espejo plano lacaniano "no refleja de la mayor parte de su sexo [femenino] más que un 'agujero" (p. 78). Al igual que el símbolo de la cabeza de Medusa, Margaret Whitford (1991) señala el modo en que la naturalización de la castración -como ausencia de pene- funciona para las mujeres de manera apotropaica para protegerse de la muerte. Al convertir a las mujeres en representantes de la muerte, los hombres intentan dominar y contener lo impensable. La mujer asume la función de representar la muerte porque ningún sistema de representación existente le permite ingresar al orden simbólico más allá de la castración.

Penelope Deutscher (1994) advierte el modo en que Irigaray argumenta que la identidad del hombre en términos de cualidades racionales y positivas depende del papel de la mujer como su Otro negativo, o espejo de lo masculino, "una especie de alter ego invertido, o de negativo, también fotográfico, y por ende negro. Opuesto, contrario, incluso contradictorio" (Irigaray, 2007, p. 15). La mujer se articula representacionalmente a partir del reflejo especular que la inscribe como lo negativo del hombre. La representación de la masculinidad como presencia y positividad depende de la oposición de lo femenino como ausencia.

La representación del espejo plano está a la base de la constitución del sujeto masculino e, incluso, todo el edificio patriarcal depende del falo. Aquello que el espejo plano relega como invisible, como lo no inmediatamente accesible a la vista, indica lo que no es totalmente propiedad de los hombres y lo que no se inserta fácilmente en las dicotomías disponibles. Así, Irigaray plantea el speculum para señalar la fuerza potencial de la elusividad e inasibilidad que podría orientarnos hacia una forma diferente de simbolizar el cuerpo sexuado. La idea de speculum se presenta como un recurso conceptual relevante, pues refiere, por un lado, a la idea de una superficie refractaria no plana y, por otro lado, al instrumental utilizado para acceder a la interioridad de cuerpo femenino mediante la vagina. Esta iluminación de una zona oscura que escapa al acceso del espejo plano lacaniano nos enfrenta, de acuerdo a Irigaray, con los límites de la representación metonímica 
del falogocentrismo - que cosifica al objeto debido, justamente, a lógica que envuelve la economía de su representación-.

Con fuertes puntos de contacto, Kaja Silverman (1988) enfatiza el modo en que la imagen reflejada en el espejo se encuentra culturalmente mediada. Su carácter externo implanta un sentido de alteridad irreductible en el mismo momento en que la identidad se delinea. La autora enfatiza que el ingreso al orden simbólico implica un costo considerable. Allí se produce la pérdida de numerosas partes que caen por fuera de la inteligibilidad que imprime la imagen ideal. La mediación cultural que regula el proceso postula el falo como significación que sostiene la completud. De este modo se produce la articulación de un sujeto masculino coherente y, al mismo tiempo, la representación de la mujer como carente. En esta lógica -que Allison Weir (1996) ha denominado sacrificial- la identificación de la mujer con la falta funciona para cubrir una ausencia estructural destinada a dañar el ideal de completud. La mujer como lo Otro es producto de un constructo simbólico en el que se concentra la diferencia, un sitio al que se le adjudica aquello incompatible con la función fálica en relación con la cual se define el sujeto masculino. Lo Otro mujer adviene como un exterior constitutivo del Sujeto varón, un espacio de producción continua del que depende el propio orden falogocéntrico. El espejo plano resulta un articulador fundamental de la representación que entreteje tal orden simbólico.

Lee Edelman (1986), por su parte, apela al espejo convexo como estrategia para sospechar del espejo plano como única posibilidad de representación del yo. Así, el problema de la representación cobra relevancia cuando la imagen del cuerpo, y su saturación normativa, advienen como único medio para la articulación de la representación del yo. Edelman destaca que la imagen corporal constitutiva del yo exige ser puesta en relación con un cuerpo real y, por tanto, original. El recorrido teórico desplegado hasta el momento apunta a poner en duda el carácter original de un cuerpo más allá de la imagen que la norma articula en el plano de la representación. En esta línea, el carácter cóncavo del espejo permite pensar la distorsión implícita en cualquier empresa de autorrepresentación. Esto es: la representación del cuerpo como totalidad da cuenta de la representación del proceso mediante el cual se representa al cuerpo como totalidad. Por lo cual la concavidad subyace al proceso mismo, problemático, de representación. 
Edelman (1986) no solo sugiere que la totalidad, lejos de ser un atributo contenido en la realidad, constituye un modo hegemónico de representar la representación, sino que el proceso de representación siempre se encuentra mediado por representaciones anteriores. Esta idea de que la representación de sí se encuentra enclavada en la imagen de un cuerpo que es, al mismo tiempo, producto de una representación, y donde la representación de la representación es la interpretación de una representación anterior de la representación, nos conduce a una sala de espejos enfrentados. Esta cadena aparentemente interminable de desplazamientos pone en problemas la representación como reflejo de la realidad, puesto que la realidad es la categoría cabalmente problematizada.

La representación de Medusa en un espejo cóncavo se postula, en este sentido, no como un reflejo de un objeto modelo, al que se le adjudican atributos reales y auténticos, sino como una maquinaria que denuncia el modo fallido en que la representación se produce. Y es así como el fragmento irrumpe en aquel punto fallido del proceso de producción de la representación.

Conclusión: la vulnerabilidad de los cuerpos nuevamente. La materialidad en la trama de violencia normativa

Si Adriana Cavarero entiende por vulnerabilidad constitutiva la carne presta a ser desgarrada a tal punto de romper la unicidad y totalidad de un cuerpo, el espectro de autores indagados en este artículo nos permite resituar la vulnerabilidad como el carácter tenue de aquellos mecanismos normativos que producen y mantienen la unicidad del cuerpo como representación hegemónica. Esta instala, a cada instante, una geografía corporal que oculta, como continente negro, otras formas corporales. La cabeza de Medusa se eleva como símbolo subversivo que emerge de todo proceso de representación. Reflexionar sobre la violencia de las normas sociales que participan en la composición de la imagen corporal conlleva la posibilidad de contornear nuevos límites y condensar sentidos inesperados en la superficie corporal -el carácter fragmentario es solo una posibilidad emergente-.

A nivel simbólico aquellos cuerpos no normativos no son totalidad; por tanto circulan bajo la valencia simbólica del fragmento. El reconocimiento de las normas sociales que rigen los procesos de representación no alcanza a aquellos 
cuerpos que, si no de-formados, se encuentran castrados del elemento totalizante ${ }^{3}$. El horror que Cavarero encuentra en un cuerpo concretamente despedazado es el mismo que, previamente, y a nivel simbólico, los cuerpos no normativos suscitan a la mirada social. Por tanto, la carnicería de los restos corporales que descomponen el todo corrobora una fragmentación corporal no tolerada que previamente existe en lo simbólico.

Adriana Cavarero encuentra el horror en la disposición concreta de un cuerpo en pedazos. Pero reflexionar sobre las implicancias simbólicas de lo fragmentario en un contexto social donde el carácter normativo de la totalidad y la unicidad organizan el campo de lo inteligible nos permite vislumbrar los modos en que opera previamente la violencia normativa que impone unicidad simbólica a los cuerpos. Si la desarticulación material de un cuerpo configura el horror, este carácter horroroso debería ser reelaborado en función de la articulación de una totalidad y unicidad simbólica idealizada propia de un orden político. Así, es posible trasladar el eje de la reflexión a una dimensión ético-política centrada en lo que Judith Butler (2010) denomina precaridad ${ }^{4}$. Para la autora, la precaridad (precarity) de la vida nos conduce a interrogarnos sobre cuáles son las condiciones en que resulta posible aprehender una vida como precaria, y sobre otras en que resulta poco posible o, incluso, imposible. Si la precariedad (precariousness) nos remite a la vulnerabilidad física de toda persona, la precaridad supone una dimensión estrictamente política sostenida sobre el registro existencial de aquella.

La precaridad refiere a la captura políticamente diferencial de la precariedad -entendida como la vulnerabilidad ontológica de todo cuerpo-. "El 'ser' del cuerpo [...] siempre está entregado a otros: a normas, a organizaciones sociales y políticas que se han desarrollado históricamente con el fin de maximizar la precariedad para unos y de minimizarla para otros" (Butler, 2010, p. 15). Esta

3 Lara Merlin (2003) sugiere que los cuerpos femeninos, codificados simbólicamente como castrados, son cuerpos heridos, y es de ese modo como cobran existencia social. Sin embargo, se trata de un cuerpo ontológicamente incompleto, pues anexar un pene allí no aportaría completud sino que, más bien, otorgaría un carácter de-formante. Entonces, los cuerpos recodificados como femeninos como las corporalidades trans no cumplen con las existencias idealizadas del espejo plano.

4 El neologismo "precaridad" se ofrece como traducción del término "precarity" que la propia Judith Butler introduce como recurso para diferenciar su sentido de aquel que adjudica a 'precariedad' ('precariousness'). 
distinción entre precaridad y precariedad resulta de extrema relevancia, pues invoca consideraciones ético-políticas que la propia Adriana Cavarero (2000) suscita en Butler (2009, 2014). Aún así, los aportes de Adriana Cavarero solo parecen contemplar aquello que Butler denomina como precariedad. Más allá de ella, la dimensión política y normativa que introduce la idea de precaridad nos permite enfatizar que

no es posible definir primero la ontología del cuerpo y referirnos después a las significaciones sociales que asume el cuerpo. Antes bien, ser un cuerpo es estar expuesto a un modelado y a una forma de carácter social, y eso es lo que hace que la ontología del cuerpo sea una ontología social (Butler, 2010, p. 15).

Si todos los cuerpos muestran una vulnerabilidad constitutiva, esto no quita que existen disposiciones sociales y normativas que exponen a algunos cuerpos más que a otros, pues "el cuerpo está expuesto a fuerzas social y políticamente articuladas, así como a ciertas exigencias de sociabilidad [...] que hacen posible el persistir y prosperar del cuerpo" (Butler, 2010, pp. 15-16). Las formas horrorosas, en diversos grados, de cuerpos que no logran inscribirse bajo la égida de las exigencias normativas de las buenas formas que pauta el ideal se encuentran más expuestas a la aniquilación. En este punto cobra cabal significación el aporte butleriano: "que una vida es dañable o que puede perderse, destruirse o desdeñarse sistemáticamente hasta el punto de la muerte" nos conduce a la dimensión de la precariedad, la cual pone en primer plano el hecho de que "la vida exige que se cumplan varias condiciones sociales y económicas para que una vida se mantenga como tal" (Butler, 2010, p. 30). Por tanto, la violencia que no se contenta con apagar la vida, sino que se propone arrojar al otro fuera de todo esquema normativo de inteligibilidad, que despedaza la materialidad del cuerpo en fragmentos para tornarlo abyecto, se apuntala en una violencia previa, normativa y simbólica, que hace precaria la existencia social de aquellos cuerpos no marcados por la idealidad.

Invocar espejos cóncavos como medio de representación renueva esperanzas de habilitar el fragmento como sitio no punible de identificación (Butler, 2008), un paso hacia la lucha por la transformación de la esfera simbólica articulada por la representación que el espejo plano produce. La resignificación de los marcos 
hegemónicos a partir de los cuales los cuerpos se tornan inteligibles socialmente, y que aquí hemos expresado bajo la imaginería de tornar cóncava la superficie plana de espejo, ofrece la posibilidad de nuevas condiciones de existencia para aquellos cuerpos que hoy se consideran abyectos. Judith Butler (2010) nos dice: si queremos ampliar las reivindicaciones sociales y políticas respecto a los derechos a la protección, la persistencia y la prosperidad, antes tenemos que apoyamos en una nueva ontología corporal que implique repensar la precariedad, la vulnerabilidad, la dañabilidad [...] y las reivindicaciones respecto al lenguaje y a la pertenencia social (Butler, 2010, p. 15).

En esa dirección se inscribe este aporte.

\section{Referencias}

Butler, J. (1989). Foucault and the Paradox of Bodily Inscriptions. Journal of Philosophy, 86, 601-607.

Butler, J. (1997). The Psychic Life of Power. Theories in Subjection. California: Stanford University Press.

Butler, J. (1999). Revisiting Bodies and Pleasures. Theory, Culture \& Society, 16(2), 11-20.

Butler J. (2007). El género en disputa. El feminismo y la subversión de la identidad. Barcelona: Paidós.

Butler, J. (2008). Cuerpos que importan. Sobre los límites materiales y discursivos del "sexo". Buenos Aires: Paidós.

Butler, J. (2009). Dar cuenta de sí mismo. Violencia ética y responsabilidad. Buenos Aires: Amorrortu.

Butler, J. (2010). Marcos de guerra. Las vidas lloradas. Buenos Aires: Paidós.

Butler, J. (2014). Vida precaria, vulnerabilidad y ética de cohabitación. En: B. Saez Tajafuerce. (Ed.). Cuerpo, memoria y representación. Adriana Cavarero y Judith Butler en diálogo (pp. 47-49). Barcelona: Icaria.

Campagnoli, M. (2013). La noción de quiasmo en Judith Butler: para una biopolítica positiva. Nómadas, 39, 47-61.

Cavarero, A. (1995). Para una teoría de la diferencia sexual. Debate Feminista, $12,152-184$. 
Cavarero, A. (2000). Relating Narratives: Storytelling and Selfhood. London: Routledge.

Cavarero, A. (2009). Horrorismo: Nombrando la violencia contemporánea. Barcelona: Anthropos.

Cavarero, A. (2014). Inclinaciones desequilibradas. En: B. Saez Tajafuerce. (Ed.). Cuerpo, memoria y representación. Adriana Cavarero y Judith Butler en diálogo. Barcelona: Icaria.

Cixous, H. (1995). La risa de la Medusa. Barcelona: Anthropos.

Copjec, J. (1989). The Orthopsychic Subject: Film Theory and the Reception of Lacan. October, 49, 53-71.

Cristóbal, V. (1989). Perseo y Andrómeda: versiones antiguas y modernas. Cuadernos de Filologia Clásica, 23, 51-96.

Deutscher, P. (1994). “The Only Diabolical Thing about Women...”: Luce Irigaray on Divinity. Hypatia, 9(4): 88-111.

Edelman, L. (1986). The Pose of Imposture: Ashbery's "Self-Portrait in a Convex Mirror". Twentieth Century Literature, 32(1), 95-114.

Felman, S. (1988). Lacan's Psychoanalysis, or The Figure in the Screen. October, 45, 97-108.

Foster, H. (2003). Medusa and the Real. Anthropology and Aesthetics, 44, 181-190.

Freud, S. (1979 [1914]). Introducción del narcisismo. En: Obras completas (Vol. XIV) (pp. 65-98). Buenos Aires: Amorrortu.

Freud, S. (1979 [1922]). La cabeza de Medusa. En: Obras completas (Vol. XVIII) (pp. 270-271). Buenos Aires: Amorrortu.

Freud, S. (1979 [1923]). El yo y el ello. En: Obras completas (Vol. XIX) (pp. 1-66). Buenos Aires: Amorrortu.

Freud, S. (1979 [1924]). El sepultamiento del complejo de Edipo. En: Obras completas, (Vol. XIX) (pp. 177-187). Buenos Aires: Amorrortu.

Fuss, D. (1995). Identification Papers. New York: Routledge.

Gallop, J. (1983). Lacan's “Mirror Stage”: Where to Begin. SubStance, 12(1), 118-128.

Hüser, R., \& Silverman, K. (1997). Crossing the Threshold: Interview with Kaja Silverman. Discourse, 19(3), 3-12.

Irigaray, I. (2007). Espéculo de la otra mujer. Madrid: Akal. 
Kirby, V. (2011).Judith Butler: Pensamiento en acción. Barcelona: Bellaterra.

Lacan, J. (1953). Some Reflections on the Ego. International Journal of PsychoAnalysis, 34(1), 11-17.

Lacan, J. (1987) El Seminario 11. Los cuatro conceptos fundamentales del psicoanálisis (1964). Buenos Aires: Paidós.

Lacan, J. (2008). El Seminario 2. El yo en la teoría de Freud y en la técnica psicoanalitica, 1954-1955. Buenos Aires: Paidós.

Lacan, J. (2009a). El estadio del espejo como formador de la función del yo [Je] tal como se nos revela en la experiencia psicoanalítica. En: Escritos I (pp. 99106). México: Siglo XXI.

Lacan, J. (2009b). Función y campo de la palabra y del lenguaje en psicoanálisis. En: Escritos I (pp. 231-310). México: Siglo XXI.

de Lauretis, T. (1992). Alicia ya no. Feminismo, semiótica, cine. Madrid: Cátedra. Lévi-Strauss, C. (1987). Antropología estructural. Barcelona: Paidós.

Linder, M. (1993). Time for Lacan: Looking after the Mirror Stage. Assemblage, $21,82-83$.

Lynch, R. (2008). The Alienating Mirror: Toward a Hegelian Critique of Lacan on Ego-Formation. Human Studies, 31(2), 209-221.

Martínez, A. (2013). 'El grano de arena en el centro de la perla'. Registros de la identificación y formación del sujeto en Judith Butler. En: M. L. Femenías, V. Cano \& P. Torricella. (Comps.). Judith Butler, su filosofía a debate (pp. 213-240). Buenos Aires: FFyL/UBA.

Martínez, A. (2015). La tensión entre materialidad y discurso: la mirada de Judith Butler sobre el cuerpo. Cinta Moebio, 54, 325-335.

Merlin, L. (2003). Perverse Ethics: The Body, Gender and Intersubjectivity. Feminist Theory, 4(2), 165-178.

Schilder, P. (1923). The Image and Appearance of the Human Body. New York: International University Press.

Silverman, K. (1993). What Is a Camera?, or: History in the Field of Vision. Discourse, 15(3), 3-56.

Silverman, K. (1996). The Threshold of the Visible World. New York: Routledge. Silverman, K. (2000). Speak, Body. Discourse, 22(2), 8-24.

Vernant, J.-P. (2000). Érase una vez... El universo, los dioses, los hombres. Un relato de los mitos griegos. Buenos Aires: Fondo de Cultura Económica. 
Wallon, H. (1975). Los origenes del carácter en el niño. Buenos Aires: Nueva Visión.

Woodward, K. (1983). Instant Repulsion: Decrepitude, the Mirror Stage, and the Literary Imagination. The Kenyon Review, 5(4), 43-66. 